\title{
Arqueología, folklore y comunidades locales: los castros en el medio rural asturiano
}

\author{
Archaeology, folklore and local communities: \\ the hillforts in the Asturian countryside
}

\author{
David González Álvarez \\ Becario FPU, Departamento de Prehistoria, Universidad Complutense de Madrid \\ davidgon@ghis.ucm.es
}

Recibido: 20-09-2010

Aceptado: 02-02-2011

\section{RESUMEN}

En este trabajo se reflexiona sobre la relación entre los arqueólogos y las comunidades locales del medio rural europeo, repasando la trayectoria y las posibilidades que ofrece la atención a los relatos orales del folklore de temática arqueológica. Para ello, se analiza al caso concreto de la investigación de la Edad del Hierro en Asturias, repasando los antecedentes de este tipo de aproximaciones y exponiendo las aplicaciones prácticas que la atención a las narraciones orales pueden aportar a la Arqueología. A la vez, se exploran algunas posibles vías por las que este diálogo abierto pudiese revertir en las comunidades locales.

Palabras Clave: Otredad. Oralidad. Multivocalidad. Folklore. Castros. Asturias.

\begin{abstract}
In this paper we reflect on the relationship between archaeologists and local communities in rural Europe, seeking to review the history and possibilities of attention to oral stories of the folklore with archaeological themes. We analyze the specific case of the investigation on the Asturian Iron Age. We review the background of such approaches and we show the practical applications that focussing on oral history can contribute to archaeological research. At the same time, we explore some possible ways in which this dialogue could revert to local communities.
\end{abstract}

KEY WoRDs: Otherness. Orality. Multivocality. Folklore. Hillforts. Asturias.

SUMARIO 1. Introducción. 2. El folklore y las comunidades preindustriales. 3. Arqueología y folklore. 4. La cosmología de las comunidades campesinas tradicionales del medio rural asturiano y los relatos orales del folklore. 5. Los moros. 6. Antecedentes en el tratamiento arqueológico del folklore relacionado con los castros asturianos. 7. Algunas aplicaciones prácticas. 8. La atención al folklore y a las comunidades locales como fuente de alteridad para la Arqueología castreña. 9. Conclusiones. 


\section{Introducción}

Los castros del occidente cantábrico constituyen hitos bien visibles en el paisaje, ya que su conspicua ubicación fue, para las comunidades prerromanas que los construyeron, un factor determinante en la elección de su localización (Fig. 1). Su marcada monumentalidad ha ralentizado su amortización; aún hoy se reconocen construcciones entre las ruinas que, en los casos más singulares, conservan alzados de varios metros (Fig. 2). Tampoco pasan desapercibidas las profundas cicatrices dejadas en el terreno por los fosos, terrazas y taludes que delimitaban los poblados, y que siguen condicionando la actual fisonomía de estos yacimientos.

Tras su abandono generalizado $-\mathrm{a}$ finales del siglo II d.C. (Villa 2008)- algunos castros recibieron reocupaciones o frecuentaciones de difícil caracterización, como hábitats esporádicos, encerraderos de ganado, espacios de cultivo de las aldeas abiertas surgidas en la transición hacia el Medioevo o como canteras abastecedoras de materiales constructivos. Sobre algunos recintos castreños se erigirían torres y fortalezas militares en época medieval, como reflejo de la importancia geoestratégica de estos enclaves. No obstante, la pretendida perduración o reocupación habitacional de los yacimientos castreños por comunidades campesinas prefeudales (Fernández Mier 1999; Gutiérrez 2002; Maya 1989: 123-136) es una hipótesis sin contrastar para nuestro área de estudio, ya que las evidencias conocidas adscribibles a momentos tardorromanos o altomedievales nunca aparecen ligadas a contextos habitacionales claros, a diferencia de otras áreas próximas (Gutiérrez 1996). Con la suma de todas estas situaciones, las ruinas castreñas serían elementos muy presentes en la cotidianeidad de los posteriores habitantes de sus proximidades, sin que esto nos lleve a hablar de continuidades sociales, culturales o identitarias. Su cercanía y visibilidad darían origen a un amplio corpus de leyendas sobre los castros y sus antiguos pobladores, que pasarían a ser protagonistas del folklore y la memoria colectiva de las comunidades campesinas del medio rural asturiano.

En este trabajo reflexionaré acerca de las narraciones orales del folklore tradicional asturiano relacionables con castros. La atención a este géne-

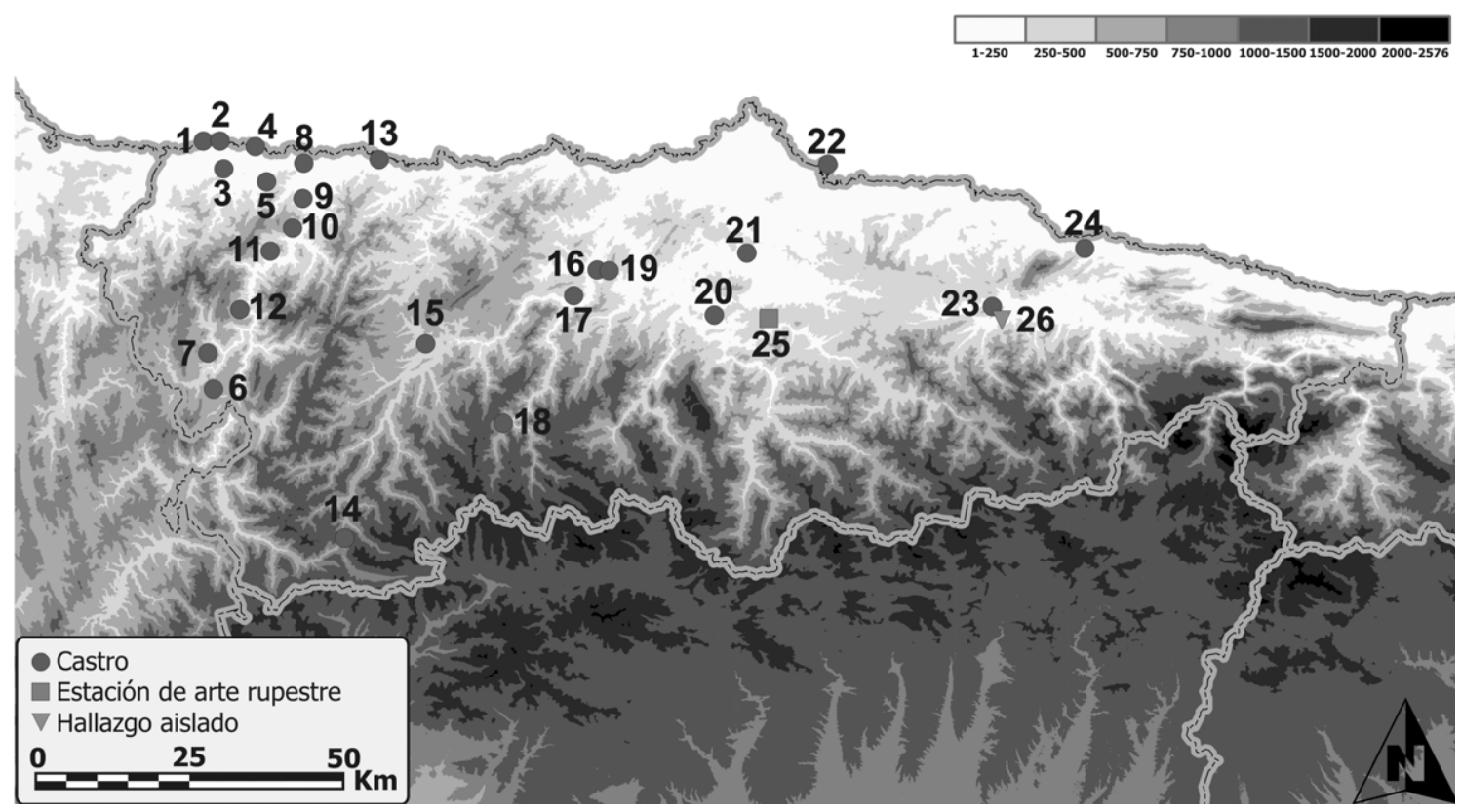

Figura 1.- Localización dentro de Asturias de los yacimientos mencionados en el texto. 1-El Toxal. 2-El Castelo d'Esteiro. 3-El Picón. 4-Cabo Blanco. 5-La Corona d'Arancedo. 6-El Chao Samartín. 7-San Isidro. 8-Mohías. 9Coaña. 10-Pendia. 11-La Escrita. 12- El Castelón de Eilao. 13-El Castiel.lo de Otur. 14-L.larón. 15-San L.luis. 16- El Castiellu de Villar. 17-El Castru de Alava. 18- El Castiel.lu de Santuchanu. 19-El Picu La Forca. 20-El Castiellu de Llagú. 21-El Cantu San Pedro. 22-La Campa Torres. 23-El Castro de Argandenes. 24-El Picu'l Castru de Caravia. 25Picu Berrubia. 26-Moñes.

Complutum, 2011, Vol. 22 (1): 133-153 


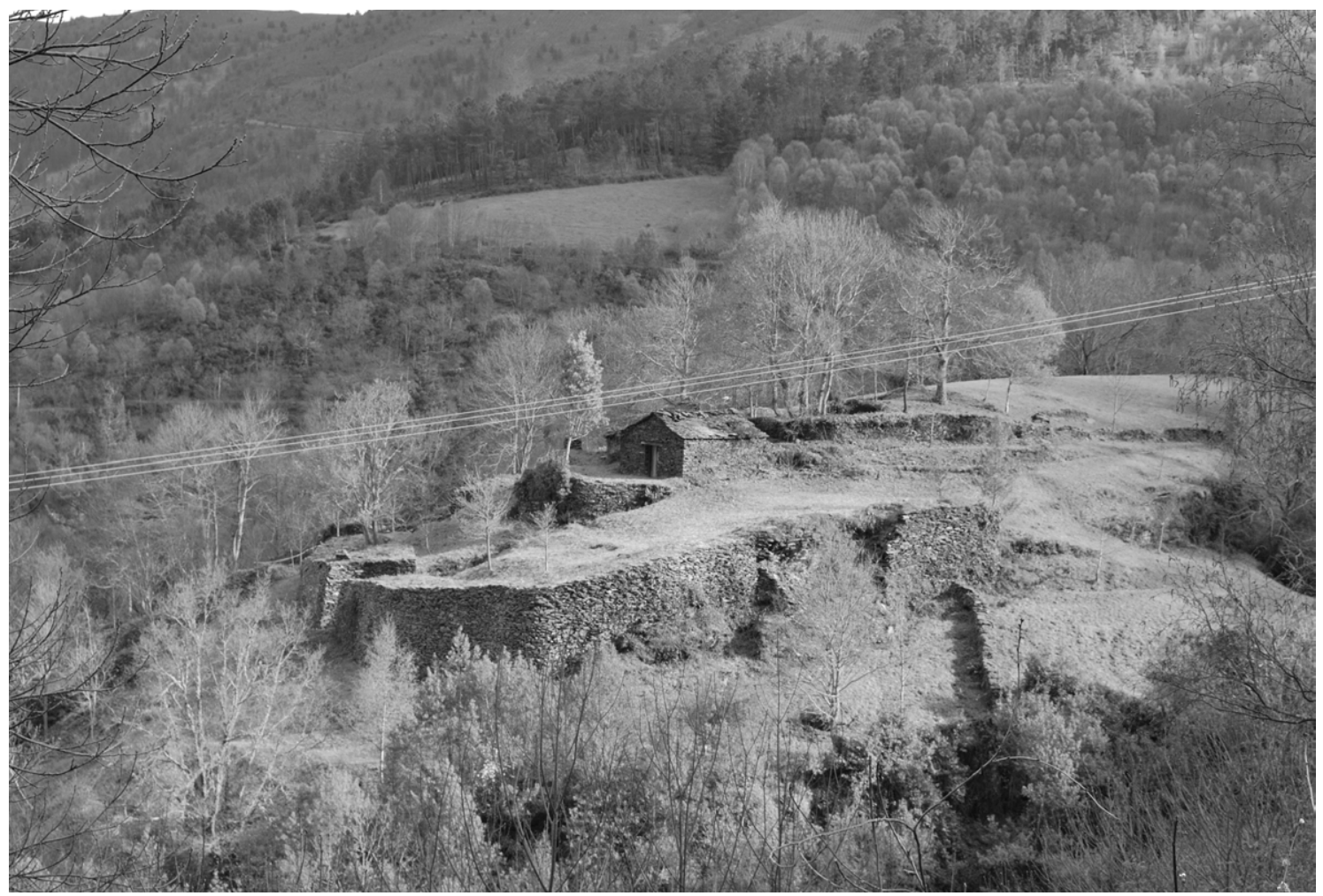

Figura 2.- El Castelón de Eilao.

ro de narraciones puede ser una vía de trabajo útil para la Arqueología, de cara a obtener nuevos datos para el estudio de estos yacimientos, además de ofrecer buenos referentes de alteridad para construir con espíritu crítico nuestras interpretaciones arqueológicas. Entender estos relatos orales como una expresión de la cosmología campesina nos permitirá valorar de forma comprensiva el sentido de estos discursos míticos en su propio contexto vivencial.

\section{El folklore y las comunidades preindustriales}

El folklore como término (folk-lore: pueblo-conocimiento) y como objeto de estudio de la Etnografía y la Antropología nace en la Europa del siglo XIX. Tal concepto puede definirse como el conjunto de conocimientos y saberes populares que las sociedades tradicionales compilan oralmente, a escala local, con un fuerte componente estático y con mínimas influencias del ámbito académico. La gente emplea estos conocimientos colectivos en su día a día a modo de esqueleto comprensivo y estructurador de su realidad vital, como bien indica el vocablo alemán Alltagskultur -vida cotidiana- (Holtorf 2005: 7). El folklore se muestra, para comunidades preindustriales como la campesina asturiana, como una parte especialmente imbricada en su propio esquema de pensamiento $\mathrm{y}$ de percepción de la realidad (Herva $\mathrm{y}$ Ylimaunu 2009: 234). Tales narraciones incluyen preceptos o enseñanzas normativas encaminadas a prevenir situaciones que comprometan la estabilidad de la comunidad, ofreciendo soluciones o formas de evitar posibles problemas, refiriéndose por ejemplo a un tiempo lejano en el que tal suceso fuera favorablemente afrontado (Forbes 2009: 98).

Los primeros acercamientos al folklore centraron su atención en las formas de vida tradicionales de los países europeos -entonces en vías de industrialización- en cuyo medio rural continuaban plenamente vigentes. Se inició la recogida de información sobre tradiciones orales, cultura material... de aquellas comunidades rurales que habitualmente fueron objeto de estudio, con cierto tono paternalista, para investigadores de extracción culta y urbana. Este registro de informaciones aumentaría 
en cantidad y calidad en paralelo al desarrollo y consolidación de disciplinas como la Antropología y la Filología, además del perfeccionamiento del método etnográfico. En la actualidad, el folklore se concibe como una expresión de la cosmología tradicional de las comunidades preindustriales (Layton 1999: 26), mejor que como una desorganizada y deslavazada colección de fragmentos narrativos de carácter legendario.

Desde una perspectiva arqueológica, podemos tomar ciertas informaciones de este tipo de trabajos elaborados por etnógrafos o antropólogos; y también con más cautela de los datos ofrecidos por eruditos locales o viajeros ilustrados (GazinSchwartz 2001: 268-269). No obstante, la mejor fuente de información para nuestros intereses la proporcionan aquellos estudios etnoarqueológicos (González Ruibal 2003b), etnohistóricos (Damm 2005: 74-75) o de Etnografía arqueológica (Castañeda y Matthews 2008; Hamilakis y Anagnostopoulos 2009) que atiendan a los relatos orales de las comunidades locales relacionando su contenido informativo con el estudio de las evidencias materiales a las que puedan vincularse.

\section{Arqueología y folklore}

La Arqueología reconstruye el pasado ordenándolo en una línea crono-temporal en la que se delimitan tiempos y épocas precisas; mientras que la tradición oral del folklore sirve a los grupos preindustriales para recrear el pasado en un paisaje construido en el presente donde ciertos personajes de rasgos legendarios protagonizan los relatos (Layton 1999: 27; Thompson 2004: 336). Las narraciones orales prestan una atención mínima a los aspectos temporales, más allá del empleo de sencillas ordenaciones categóricas. Un buen ejemplo de esto lo encontramos en la región portuguesa de Alto Minho, donde los campesinos manejan un esquema basado en un ahora, que se corresponde con el tiempo presente y con la gente; el antes, que sería el tiempo pasado del que se tienen recuerdos directos a través de parientes o vecinos de las generaciones inmediatamente anteriores, protagonizado por los viejos; y un genérico antiguamente, que se proyecta hacia los tiempos más lejanos, cuando los antiguos poblaban el mismo escenario que habitan los actuales campesinos (Pina-Cabral 1989: 62). Este esquema sería equivalente al empleado por los campesinos del medio rural asturiano, para quienes los moros desempeñarán el rol de los antiguos. Esos protagonistas míticos del horizonte temporal más distante suelen aparecer vinculados a hitos bien reconocibles en el paisaje -muchos de ellos yacimientos arqueológicos-, algo común a diferentes tradiciones orales preindustriales (por ejemplo, Herva y Ylimaunu 2009: 238). Esto resalta el importante papel de la materialidad en la fijación y transmisión de la memoria entre las poblaciones ágrafas (Rowlands 1993; Santos Granero 1998), lo que justifica el interés de una aproximación arqueológica al folklore.

Si la Arqueología se sustenta sobre un código lógico basado en criterios empíricos, el folklore funciona en conexión con las claves míticas de la cosmología preindustrial campesina. Un nexo de unión entre las dos opciones de conocimiento es el hecho de que ambos discursos traten de reconocer el origen de ciertas evidencias materiales observables, como los yacimientos arqueológicos. Buscan desentrañar su autoría, finalidad o funcionamiento, y asumen las respuestas en el mismo código cosmográfico que estas comunidades mantengan como mecanismo de seguridad (sensu Hernando 2002). En este sentido, las tradiciones orales del folklore y los discursos arqueológicos serán construcciones de conocimiento igual de satisfactorias para sus autores y consumidores, pues cada vía mostrará coherencia interna con la estructura de pensamiento que soporte cada construcción intelectual. No obstante, conviene remarcar cómo el conocimiento tradicional del folklore tiene un determinado contexto de validez, al funcionar sólo para un ámbito cultural y geográfico concreto, como una parroquia o un valle, mientras que el conocimiento empírico de la Arqueología suele tener pretensiones universales (Lane 2006: 72).

Debido a ciertas coincidencias en sus objetos de atención, el acercamiento al folklore puede ser un provechoso punto de partida para la Arqueología, desde donde ya se han realizado múltiples aproximaciones optimistas a la tradición oral en diferentes contextos investigadores (Barrowclough y Hallam 2008; Bielawski 1994; Dods 2004; EchoHawk 2000; Gazin-Schwartz y Holtorf 1999a; Glazier 2007; Herva y Ylimaunu 2009; Hrobat 2007; Moore 2008; Thompson 2004).

$\mathrm{Si}$ asumimos las anteriores premisas, y tomamos como referentes los antecedentes investigadores citados, es hora de pasar a trabajar desde una 
perspectiva incluyente y de diálogo entre las partes, para ahondar en el entendimiento entre cada una de ellas. En mi opinión, existe la posibilidad efectiva de relacionar ambos campos para avanzar en el conocimiento sobre las comunidades humanas: tanto las pretéritas como las actuales. Con la asunción de esta propuesta, trataré de emplear en mi trabajo el conocimiento y la percepción mítica que generan (o generaron) las comunidades campesinas tradicionales del entorno inmediato en el que viven (o vivieron), como una fuente de información más -tras un necesario análisis crítico-que aporte nuevos datos al proceder interpretativo de la Arqueología. No obstante, esta aproximación debe ser cautelosa, pues debe considerar y respetar el sentido emic que las narraciones orales del folklore tienen en $\mathrm{su}$ propio contexto cultural (Mason 2000: 263-264). A modo de ensayo, esbozaré de aquí en adelante una somera aproximación a esta vía de trabajo en el marco del estudio de la Edad del Hierro en el medio rural asturiano que profundice tentativas anteriores (Álvarez Peña 2002, 2007; González Álvarez 2008). Mi propósito será integrar informaciones derivadas de la atención a los relatos orales relacionados con yacimientos castreños en las interpretaciones arqueológicas actuales, compartiendo la apreciación de que la búsqueda de cuantas más fuentes informativas [y cuanto más diversas] sea posible acerca del objeto de estudio, debe ser una obligación para el investigador (Mason 2000: 262).

\section{La cosmología de las comunidades campesi- nas tradicionales del medio rural asturiano y los relatos orales del folklore}

Todos los hombres y mujeres han de poder asumir su posición en la realidad que les haya tocado vivir, manteniendo una consciencia -de si mismos y de su entorno- $y$ un determinado aparato reflexivo que les permita comprender su lugar en el mundo, sin que la situación les abrume. Según Almudena Hernando (2002), todos los seres humanos generamos unos mecanismos de seguridad que nos ayudan a sentirnos a salvo en el transcurso de nuestra existencia, que pueden agruparse bajo el concepto de Identidad. Se utilizan, con este fin, sistemas orientativos y ordenadores de lo observable que ayuden a componer y recrear la realidad percibida. En el centro de estos esquemas se sitúan los conceptos de tiempo y espacio, que son elaboraciones humanas y no elementos dados o comunes a todas las sociedades, cuya modelación depende de la complejidad de cada cultura (Hernando 1999: 25). Existirá una relación entre el control material efectivo de su supervivencia -en cuanto a la capacidad de planificación y previsióny las modalidades que el tiempo y el espacio adquieran en cada esquema de pensamiento, que será común a todos los miembros del grupo social que participen de unas mismas condiciones de control material sobre la realidad (Hernando 1999: 89). Con esto, se considera la existencia de diferencias intragrupales relacionadas con diferentes categorías de poder: político, socioeconómico, de género, étnico, de edad... (vid. Díaz-Andreu et al. 2005).

Hasta mediados del siglo XX las formas de vida de las comunidades campesinas del medio rural asturiano se podrían caracterizar como profundamente conservadoras, en cuanto al mantenimiento de un sistema vital fuertemente arraigado en ese espacio, con una notable inmutabilidad de sus características formales (García Fernández 1980; García Martínez 2008; González-Quevedo 2002). La familia, las formas productivas, las fórmulas de socialización vecinal, la cosmovisión y la autoconsciencia personal y colectiva seguían respondiendo a unos patrones moldeados tras una larga sucesión de generaciones. Su validez y continuidad no se habían cuestionado desde el interior de estas comunidades, ya que la minimización e invisibilización de los posibles cambios de sus componentes estructurales son los pilares fundamentales del éxito en la coherencia y supervivencia de esta cosmovisión. En este contexto, el tiempo como parámetro ordenador de la realidad pierde visibilidad frente al componente espacial, sobre todo si pensamos en segmentos temporales más amplios que la vida humana. Lo espacial será el principal referente ordenador de las normas, narraciones, recuerdos $\mathrm{y}$ ensoñaciones de los grupos preindustriales (Hernando 2002). La sociedad tradicional asturiana empleará el pensamiento mítico como mecanismo estructural de seguridad y como fórmula fundamental para comprender su realidad. La gente mitifica la naturaleza percibida para obtener explicaciones, justificaciones y orientaciones en los casos que así lo necesite. Las narraciones orales elaboradas en clave mítica son parte de sus mecanismos de seguridad, por lo que la inclusión de ele- 
mentos de temática arqueológica en dichos relatos debe contemplarse a la luz de tal marco de pensamiento. Estas observaciones pueden hacerse extensibles a toda la orla cantábrica (Fernández de Rota 1984; Lisón 1977; Rivas 1991).

Con la aparición de la documentación escrita y la asimilación del carácter empirista de la Ciencia, se iniciará un cambio, a nivel estructural, en el esquema identitario campesino. Esta dinámica situación de cambio cultural se inicia a mediados del siglo XX, con la extensión de las formas institucionales y administrativas del sistema de poder del estado español contemporáneo y con la asimilación de las formas capitalistas de producción. De entonces en adelante, la confianza en el nosotros mismos, como individuos pertenecientes a una comunidad -global, a nivel casi de especie-capaz de observar el funcionamiento de la realidad, anticiparse a ella, y actuar en consecuencia, será el mecanismo básico de seguridad. Esto hará que se valore positivamente el cambio, rompiendo con la tradicional valoración del estatismo, la permanencia, y el mantenimiento invariable de lo conocido como mecanismos de seguridad (Hernando 2006: 226). Tras este profundo cambio cultural, se desvanecerá la función identitaria del discurso mítico del folklore. Su desprestigio iniciará un implacable proceso de rechazo y olvido de la tradición oral, que ha abocado a este elemento inmaterial del patrimonio cultural asturiano a su cercana extinción.

\section{Los moros}

En el imaginario popular del medio rural asturiano los moros o mouros son una categoría referencial de seres paganos (desde la óptica cristiana) con cierta variabilidad de matices. Estos míticos seres son figuras sobrehumanas que poblarían antaño el actual paisaje aldeano. Su identificación no está directamente relacionada con los musulmanes de la fase de dominio político islámico de la Península Ibérica, ni con los moriscos o los sarracenos de época moderna, ni con los cabileños de las guerras de Marruecos, ni tampoco con los rifeños enrolados en los cuerpos de Regulares del ejército de África, que actuaron en Asturias para aplacar la revolución obrera de 1934, tras la sublevación militar de 1936 y en la posterior represión de la dictadura fascista (Álvarez Martínez et al. 2007a) (Fig. 3). Incluso se establecen equivalen-

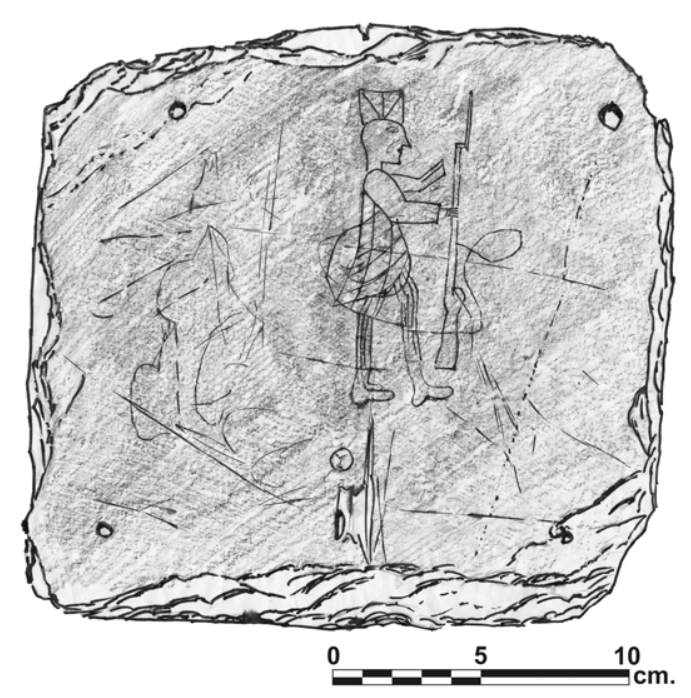

Figura 3.- Grabado con la representación de un moro del cuerpo de Regulares hallado en una casa tradicional de Priero (Salas, Asturias) (dibujo: Armando Graña).

cias entre moros y soldados franceses o combatientes carlistas. Podemos ver su polivalencia en un texto de José Arias y Caunedo (1884), autor procedente del ámbito culto y urbano que comenta la existencia de leyendas sobre chalgas o tesoros en el municipio de Teberga. A su juicio eran invenciones de los sencillos montañeses que todo se lo creen (...) mejor que el Evangelio. El autor recoge relatos de moros, tesoros y episodios de las guerras contra los franceses o carlistas, pasando de unos casos a otros con demasiada ligereza, hasta crear una amalgama en la que moros, franceses y carlistas parecen fundirse en una misma figura legendaria (Arias y Caunedo 1884: 11-14), reconocida con facilidad en algunos relatos orales que aún pueden escucharse en el medio rural asturiano.

Hombre: Un castro, efetivamente, pero ta no medio del monte, nun sé si podrás ir velo (...) Ehí habitaron os moros, na guerra civil, esta guerra última que hubo [...] unos moros ahi que tiñan caballerias, taban acampados ehi y entonces tiñan un canal para baxarlos a beber abaxo a unha fonte qu'hai ahi debaxo en medio do monte, un riachuelo...

Mujer: Ei dicen que quedóu ouro enterrado en ese castro (...) Sería d'aquela, chegaron a sacalo los moros e claro, non lles deu tempo a levarlo, tuveron qu'escapar

$\mathrm{H}$ : Ahora está cercado cunha valla todo alrede- 
dor, cunha valla como si dijéramos con una pala (...) Podes entrar, podes, ta aberto pero ta todo escavao (...) escavado ao redore (...)

M: Después por un rao abaxo, dixéronme, eu nunca o vin, pues tamén hai un... pe baxar as caballerías a beber

$\mathrm{H}$ : Bueno, pero baxarlas algo escondidas, sí, que nun se viran. Ye despóis dentro, pois tenían vivienda, tenian viviendas pras caballerias, tenian vivienda pra eles. Veise a figura d'afora, ahora de dentro...

Conversación entre un matrimonio de Casa do Toxal en Folgueiras dos Coutos (Ibias, Asturias), 22/11/2009

Los moros del imaginario campesino tomarán rasgos de todas estas realidades que se acumularán en su caracterización a modo de palimpsesto narrativo. Tal designación sustituiría a otras anteriores, como gentiles, antiguos, galigriegos, griegos o gigantes (Álvarez Peña 2007: 225-226; Arizaga y Ayán 2005: 313-314, 2007: 460-471; Ayán 2005: 92-93; González Reboredo 1971: 19-25). La denominación moros se impondría, finalmente, debido a que frente a las diferentes acepciones del término antes citadas, constituían la categoría humana más exótica de entre las conocidas por los hombres y mujeres del campo asturiano. Otras denominaciones serían posteriormente introducidas en los relatos desde ambientes eruditos, como se intuye en la confusión e incluso equiparación entre moros y romanos. Los celtas no aparecerían a nivel popular hasta un momento reciente (Marín 2005b: 309311), como una aportación proveniente de círculos cultos y urbanos, como sucedería en otras partes de Europa (Collis 2003).

Los aldeanos actuales no se ven como descendientes de los moros: ambas poblaciones formarían parte de razas distintas (Llinares 1990: 78). Una fórmula útil para comprender el sentido de los moros en el folklore tradicional asturiano es su equiparación con el otro. La cosmología campesina se caracteriza como fuertemente conservadora, por lo cual reforzarían su propia identidad con la otredad otorgada a ciertos seres míticos presentes en su paisaje simbólico. Estos relatos les servirían para explicar ciertos rasgos de su mundo, como la existencia de ruinas -yacimientos arqueológicoso para comprender componentes de su memoria colectiva desconectados de su cotidianeidad, como narraciones sobre acontecimientos lejanos, guerras o referencias a realidades socioeconómicas distintas a la suya. La contraposición de las propias costumbres a las de un pueblo extraño, incluso con la oposición de rasgos físicos, son construcciones narrativas universales entre las comunidades preindustriales, ya que la definición del otro es parte consustancial de la construcción del nosotros (Bartra 1996). Se han descrito ejemplos de esto en los Balcanes (Hrobat 2007: 35-38), América (Viveiros de Castro 1996: 123-127), Portugal (Pina-Cabral 1989: 65-66) o Escandinavia (Herva 2009: 392), entre otros casos.

El término moros también fue útil para los intereses de la Iglesia, al reforzar con su uso la condena de ciertos cultos paganos practicados en los espacios simbólicos destacados, como peñas, fuentes, árboles singulares o yacimientos arqueológicos. Estos procesos se iniciarían desde los primeros momentos del cristianismo (Fernández Conde 2000: 498-499), aunque la reacción de la institución religiosa ante el paganismo recobraría fuerza en algún momento de época bajomedieval o moderna (Ayán 2005: 103; Marín 2005a: 100). Buena muestra de esta actitud cristianizadora es la construcción de ermitas o capillas junto a castros (González 1978: 240-250) o túmulos (González 1958: 67-69; Vega del Sella 1919); la cristianización de fiestas y romerías del calendario pagano; o la generación de narraciones legendarias en las que sus protagonistas -Pelayo, Santiago u otros santos- vencerían en sus enfrentamientos con los moros. Esto también se refleja en los hagiotopónimos de castros como San L.luís, San Isidro, El Chao Samartín o El Cantu San Pedro.

Estos fenómenos asimiladores no suponen una novedad en la configuración mítica de los paisajes preindustriales de la región a lo largo del tiempo. $\mathrm{Al}$ igual que muchas capillas se asientan sobre las ruinas de poblados de la Edad del Hierro, algunos castros se relacionan con monumentos de fases anteriores. Yacimientos como El Picu La Forca (Camino et al. 2009) se levantan en espacios inmediatos a necrópolis megalíticas (de Blas 1977). En otros casos, se relacionan con monumentos naturales que bien podrían tener significaciones especiales para los grupos precastreños, como se ha propuesto para el primer recinto de El Chao Samartín, fundado al pie de una destacada roca de formas caprichosas frente a la cual ardió insistentemente una hoguera (Villa y Cabo 2003). Comprender el sentido de las construcciones orales generadas por 
el campesinado puede servirnos a los arqueólogos no sólo como una fuente informativa más en nuestro acercamiento al paisaje escenario de nuestras pesquisas. También puede proporcionarnos referentes sobre los que apoyar nuestras interpretaciones sobre el valor de los monumentos naturales o los yacimientos arqueológicos pretéritos -del Neolítico o la Edad del Bronce- en la Edad del Hierro (vid. Bradley 2002; Hingley 1996).

\section{Antecedentes en el tratamiento arqueológico del folklore relacionado con los castros asturianos}

Hasta la fecha, diferentes autores han vuelto su mirada hacia los relatos del folklore al estudiar el fenómeno castreño en Asturias. Además de evaluar la relación entre Arqueología y las comunidades locales, el repaso de la utilización de los referentes orales puede servirnos como un buen elemento de reflexión acerca del fondo epistemológico de las distintas aproximaciones a la Edad del Hierro asturiana.

El castro de Coaña, en Villacondide, es un yacimiento señero en la investigación castreña de la región. La primera intervención reglada sobre este enclave la realizaría José María Flórez a finales del siglo XIX, publicando la primera memoria de excavaciones de un castro asturiano (1878). En la exposición de los resultados de su primera campaña, el autor presta especial atención a las tradiciones orales recogidas en torno al poblado, incluyéndolas en el cuerpo explicativo de sus indagaciones. Sin embargo, Flórez no consigue separar adecuadamente folklore de Arqueología, sino que más bien crea una amalgama de ambas fuentes de conocimiento que no logra individualizar del todo (Marín 2005a: 97). Como claro ejemplo, Flórez busca en el castro de Coaña las evidencias del antiquísimo castillo que coronaba su cúspide, según tradición del país (1878: 7), intentando justificar las observaciones preliminares que apoyarían tal hipótesis. Incluso considera testimonios orales a la hora de establecer la cronología de abandono del yacimiento, ya que los abuelos de los abuelos de entonces habian visto el castillo en pie (1878: 10), aunque abandonará tal idea al documentar monedas romanas y fragmentos de terra sigillata.

Ya en el siglo XX, Aurelio del Llano excavó en El Picu'l Castru de Caravia, iniciando sus trabajos en la vertiente meridional del castro, donde las leyendas situaban la entrada a un palacio subterráneo de los moros (1919: 32-34). Es interesante ver cómo Del Llano (1919: 34) toma estas leyendas como indicios útiles para la planificación de su intervención, mencionando que así lo habían hecho los hermanos Siret en Murcia y Almería. Con esto se entrevé que el autor separa claramente la naturaleza de ambos tipos de fuentes informativas, lo que supone un paso adelante respecto a los planteamientos de Flórez, mostrando la progresiva consolidación de la Arqueología como disciplina científica.

Tras la Guerra Civil, Antonio García y Bellido y Juan Uría Ríu excavarán en Coaña (García y Bellido 1941, 1942a), Pendia (García y Bellido 1942b) y La Escrita, a resultas de lo cual los castros asturianos cobrarán gran protagonismo en el panorama investigador nacional. Sus publicaciones apenas hacen referencia a las tradiciones orales del entorno, más allá de mencionar las habituales búsquedas de tesoros de los lugareños en los yacimientos, algo que citan simplemente como una molestia para la práctica arqueológica.

A mitad del siglo $X X$, se reactiva la atención a los castros asturianos, aunque los estudios resultantes fueron muy deficientes en lo metodológico, con un notable retroceso en la calidad de las investigaciones respecto a trabajos previos (Marín 2004: 85-86). Estas intervenciones las conducirían eruditos locales y aficionados de extracción burguesa, en castros como La Escrita y La Corona d'Arancedo (Fernández Buelta 1949, 1950), El Castelo d'Esteiro y El Toxal (Labandera 1969a, 1969b, 1970, 1974) o Mohías (Martínez Fernández 1970; Martínez y Junceda 1968). El punto común a este grueso de labores es la ausencia de cuestionamientos previos al trabajo de campo. Su atención al folklore suele limitarse a mencionar la existencia de leyendas relacionadas con los castros, hablando por ejemplo de fortificaciones morunas, en las que se ocultaban celosamente tesoros fabulosos [por lo que algunos castros] han sido profanados por la fiebre insensata de los buscadores de tesoros (Labandera 1969a: 62-63). Pasajes como éste transmiten el desprecio con el que alguien ostentosamente culto, de extracción burguesa y urbana contemplaba las acciones insensatas de los campesinos iletrados alentados por cuentos y supersticiones. Esta fase de las investigaciones arqueológicas castreñas supuso un claro retroceso en la intercomunicación entre las comunidades locales y la Arqueología. 
En la misma época, y como clara contraposición a los ejemplos anteriores, destacará la figura de José Manuel González, investigador de formación filológica que tendrá muy en cuenta la toponimia y los relatos del folklore en su monumental obra de prospección y catalogación de los castros asturianos (1966, 1973). En sus pesquisas, y en las de anticuarios de la época como Joaquín Manzanares, la documentación de yacimientos u objetos arqueológicos va siempre pareja a la recogida de testimonios orales relacionados (vid. González y Manzanares 1959). Este tipo de aproximaciones, bastante comprensivas hacia el folklore, considerará la tradición oral como un indicador más a tener en cuenta en las tareas de prospección y catalogación de nuevos yacimientos o materiales, estrategia que arraigará con fuerza en la tradición prospectora asturiana.

Las siguientes aproximaciones serán las realizadas por arqueólogos procedentes de la universidad u otros ámbitos académicos, que inaugurarán las líneas actuales de investigación arqueológica sobre la Edad del Hierro en Asturias. Como antecedente inicial, Francisco Jordá Cerdá dirige excavaciones en La Corona d'Arancedo, Coaña y San L.luís, aunque sus trabajos no serían publicados hasta años más tarde. Posteriormente, se excavarán los castros de L.larón (Maya y de Blas 1983), La Campa Torres (Maya y Cuesta 2001) y se iniciará una segunda fase de trabajos en San L.luís (Jordá Cerdá et al. 1989; Jordá Pardo 2009). A este primer bloque de investigaciones realizadas desde departamentos universitarios les seguirán otros proyectos de excavaciones realizadas a finales de la década de 1980 y en la de 1990 en torno a la ría de Villaviciosa (Camino 1997, 2003), en el Occidente asturiano (Carrocera 1990, 1992, 1994; Villa 2002, 2005, 2007b) y en El Castiellu de Llagú (BerrocalRangel et al. 2002; López González et al. 1999). Recientemente, se han realizado otras intervenciones de menor envergadura (por ejemplo, Camino et al. 2009; Fanjul et al. 2009). Salvo excepciones, en estas investigaciones no se presta excesivo interés a las leyendas vinculadas con los yacimientos estudiados. En el mejor de los casos, tales relatos se presentan a modo de curiosidades, como anexos o como un campo más de los inventarios de yacimientos. Su papel es más bien anecdótico en los procesos de interpretación arqueológicos, aunque tienen un peso importante en la localización de nuevos yacimientos (vid. Camino 1995; Fanjul
2005). El creciente enfoque procesualista de la Arqueología regional y su fuerte preocupación por la recuperación y estudio de datos empíricos puede ser la causa de que el folklore vinculado a los castros haya quedado relegado en la investigación de la Edad del Hierro, ante la pretendida solidez informativa que proporcionarían los análisis físico-químicos o las tipologías de materiales. Sin embargo, encontramos unos pocos trabajos que sí han planteado una relación dinámica entre Arqueología y folklore (Álvarez Peña 2002, 2007; de Blas y López 2001; Suárez 2001) que servirán de excelentes apoyos en la apuesta por interrelacionar ambos géneros discursivos.

\section{Algunas aplicaciones prácticas}

La tradición oral campesina puede ofrecer nuevos datos a la investigación arqueológica, si atendemos al contenido informativo que estas narraciones nos desvelan por si mismas. Las leyendas relacionadas con yacimientos arqueológicos mencionan reiteradamente la aparición de tesoros, chalgas o ayalgas. Incluso ofrecen datos contextuales de la naturaleza de los hallazgos, lo que nos permite reconocer, por ejemplo, asociaciones de materiales con sectores concretos de yacimientos. Los habitantes del entorno de algunos yacimientos se encontrarían fortuitamente con objetos que no se corresponderían con los que estaban familiarizados en su vida cotidiana, por lo que explicaban su razón de ser reinterpretando comprensivamente sus características y funciones de modo que tuviesen un mínimo sentido en los términos de su propia experiencia. Testimonios de este tipo pueden escucharse aún hoy en el medio rural asturiano:

Una vez, en esa casa, los viejos, tenían una finca qu'hai hi pegada, que chaman El Castru tamién, tenemos nós outra, que amenestréila you. Ya... ya alcontranon una vasija con... ya tapada. Ya era un sábadu, que taban arando ahi pa semar pal centén ya ";Oi!" dijo'l vieju “'Oi! hai qu'esparcela por... por encima de lo arao". Ya'l outru día cuando iban a misa relucía alli todo... eso. Ya topóu mi padre fayendo la entrada pa esa finca tamién herramientas, herramientas pero de... pero ¡vaya! ¡ya de fundición! ¿eh? un hacha, pero, de cuantos años taba toda osidada ya... ya unas varillas. Ya había... diulo a un ferreiru d'Ablaneda. 
Alli houbo... ya traían l'agua, nu sei d'onde dician que la traían. You nu sei.

Testimonio recogido en Figueras

(Ayande, Asturias), 30/5/2010

La reiteración de este tipo de hallazgos acabaría por desencadenar una auténtica fiebre de oro en torno a los yacimientos arqueológicos y otras localizaciones, como cuevas, fuentes o rocas singulares, donde los moros habrían ocultado sus riquezas al huir ante el avance de la Reconquista. Aparecerán verdaderos especialistas, denominados chalgueiros dedicados en tiempo y alma a la búsqueda de tesoros (Suárez 2001: 51-60, 91-93). Por toda la región circularán documentos, conocidos como gacetas, con indicaciones precisas para localizar dichas ocultaciones. Sus poseedores protegían celosamente estos catálogos de tesoros, tras haberlos obtenido de personajes procedentes de lugares lejanos, como soldados rifeños, cristianos cautivos en Argel u Orán, moros de Jerusalén, o directamente del Archivo de Simancas (González Reboredo 1971: 71; Suárez 2001: 46-48), con lo que su origen aunaba exotismo y verosimilitud.

Al examinar distintos compendios del folklore asturiano, podemos obtener una serie de posibles asociaciones, reconocidas ya por diferentes autores (Álvarez Peña 2007; de Blas y López 2001; Suárez 2001); también para la vecina Galicia (Arizaga y Ayán 2005, 2007). Lingotes, barras de metal, hachas broncíneas y piezas líticas pulimentadas suelen interpretarse como juegos de bolos realizados en materiales preciosos, fundamentalmente oro. Distintas menciones a animales (cabras, bueyes, gallinas, cerdos...) podrían corresponderse con fíbulas, apliques decorativos, o estatuaria zoomorfa. Los característicos torques áureos de las comunidades castreñas del Noroeste peninsular serían collares, aldabones, picaportes, tiradores de cajones o asas de calderos (Álvarez Peña 2007: 228229). Las arracadas y pendientes amorcillados servirían a los míticos moros como aretas para la nariz (Álvarez Peña 2007: 230). Las diademas serían coronas de las princesas moras. Las menciones a tesorillos de monedas se corresponderían con hallazgos fortuitos que contribuirían a reforzar las leyendas de tesoros, como los de La Corona d'Arancedo (Bouza Brey 1963: 46); mientras que las ollas con cenizas u oro en polvo serían contenedores cerámicos. Se habla de lápidas con inscripciones en árabe o lengua mora, que podrían relacio- narse con piezas muebles de la plástica castreña, bien conocidas para el Noroeste (González Ruibal 2006-2007: 396), mejor que la hipótesis, también factible, de que fuesen epígrafes latinos (Álvarez Peña 2007: 231). Algunas pinturas o grabados rupestres de época prehistórica se tomarían como textos en clave que los moros habrían dejado al marchar precipitadamente tras su expulsión por los reyes asturianos, señalando el oro escondido que habrían de recuperar a su vuelta, como el caso de Picu Berrubia (de Blas 1974-1975: 65-66) (Fig. 4).

En los relatos del folklore también se contemplan algunos materiales arqueológicos como objetos de usos mágicos (Gazin-Schwartz 2001). En el medio rural asturiano estaba extendida la creencia en las atribuciones mágico-religiosas de las hachas líticas pulimentadas, que además de en contextos neolíticos y megalíticos también aparecen en castros (de Blas y Maya 1974). Dichas herramientas son conocidas como piedras de rayu y se les otorgaba la función de alejar las tormentas o curar animales enfermos. Esto explica su frecuente aparición en establos (Hevia 1997), donde habrían sido llevadas tras hallazgos fortuitos o expolios de yacimientos.

Las estructuras más destacadas de los castros cantábricos son sus líneas defensivas. Dado su grado de monumentalidad, estos elementos no han pasado desapercibidos, y así se anclan a ellos leyendas que tratan de darles explicación. Existe un peculiar relato relacionado con el castro costero de El Castiel.lo de Otur, donde sus espectaculares cinco líneas defensivas con fosos, murallas y parapetos serían los restos de un vano intento de los moros que lo habitaban por convertirlo en isla para huir de un rey cristiano. Una historia equivalente se vincula al castro de Cabo Blanco (Camino 1995: 73-74, 98).

Los relatos orales aluden también a palacios o castillos en los que vivieron los míticos moros. Dado que usualmente no se pueden contemplar buenos alzados de las cabañas castreñas, se cita la existencia de residencias subterráneas bajo los propios yacimientos arqueológicos. Mientras tanto, las ruinas de las típicas cabañas circulares son interpretadas como hornos metalúrgicos.

Algunas narraciones del folklore se refieren a sucesos históricos protagonizados por los míticos moros, como batallas entre los habitantes de diferentes castros o descripciones sobre sus modos de vida. No obstante, su validez como fuentes informativas sobre las comunidades castreñas es discutible, dada la enorme amplitud temporal que media 

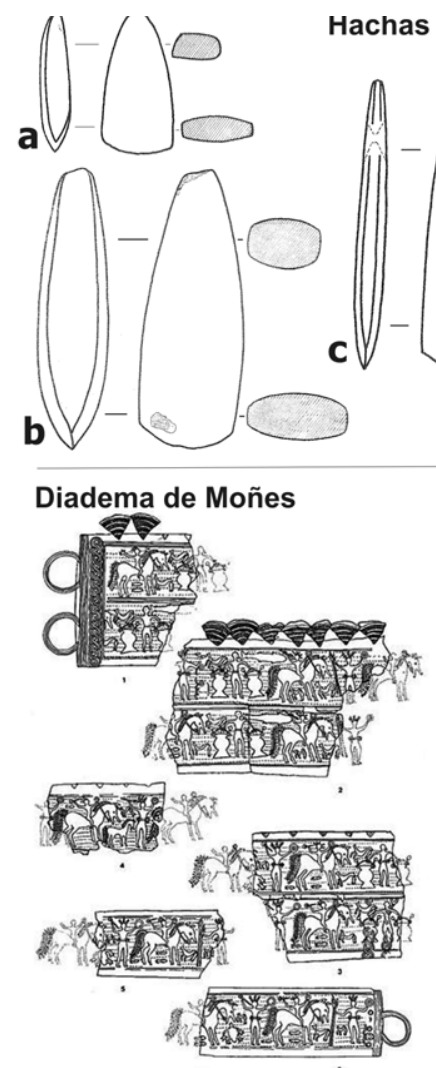

Hachas pulimentadas

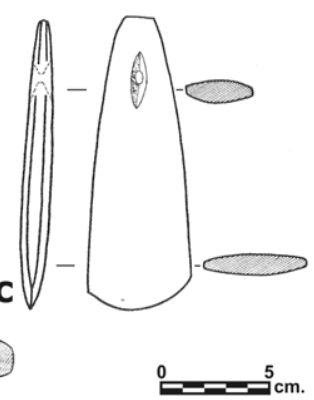

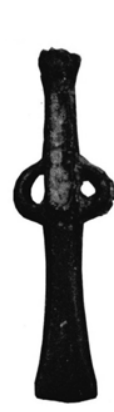

a

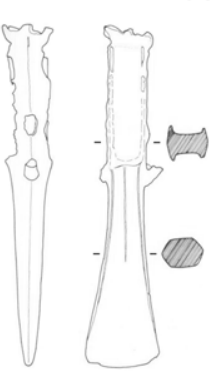

b
Hachas broncineas

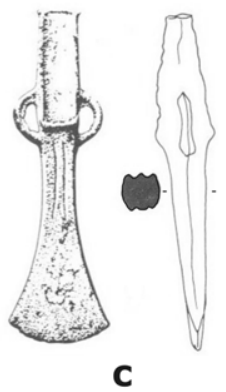

Plástica de tradición castreña
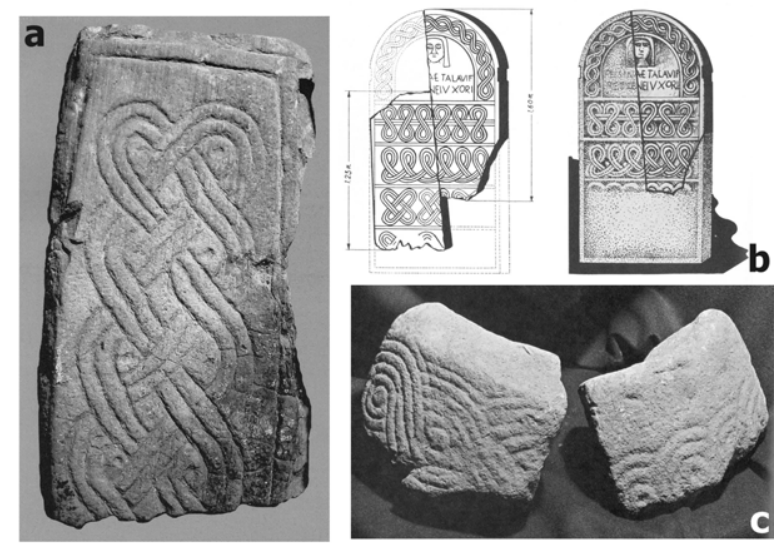

Torques castreños

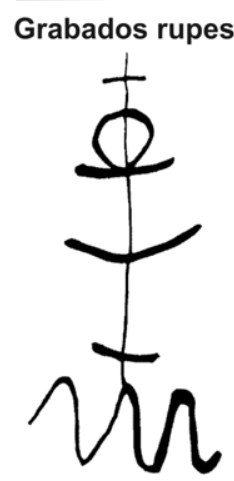

a
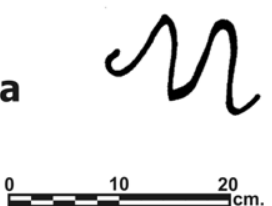
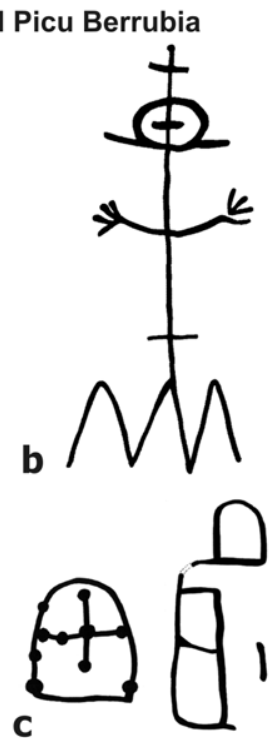
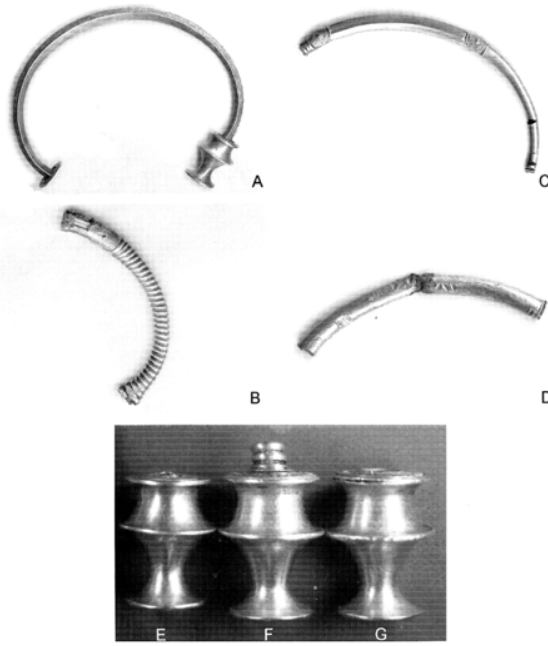

Figura 4.- Ejemplos de materiales arqueológicos que podrían identificarse en la tradición oral. Hachas pulimentadas. a-b: El Picu'l Castru de Caravia; c:Pendia (de Blas y Maya 1974). Hachas broncíneas. a-b: El Castru de Alava; c: El Castiel.lu de Santuchanu (de Blas 1983; de Blas y Villa 2008). Diadema de Moñes (Pingel 1992). Plástica de tradición castreña. a: Pieza escultórica de El Castro de Argandenes (Caso Blanco 2007); b: Estela de El Castiellu de Villar (González 1978); c: Fragmentos de un molino circular decorado de Coaña (González 1978). Grabados rupestres del Picu Berrubia (de Blas 1974-1975). a-b: Antropomorfos de la Zona 1; c: Esteliformes de la Zona 6. Torques castreños. a-g: Fragmentos de torques de la colección Soto-Cortés (García Vuelta 2001). 
entre ambos contextos humanos, entre los que las continuidades son difíciles de contemplar. Es más interesante tratar de comprender el origen y las claves explicativas de los relatos del folklore en el propio contexto sociocultural en el que surgen, se transmiten y se consumen: dentro de la esfera vital del medio rural campesino (González Reboredo, en Aparicio 1999: 330). Este tipo de narraciones constituirían, más bien, reafirmaciones de la estabilidad e inmutabilidad de las formas culturales de las comunidades tradicionales, dotando de rasgos opuestos a los propios a las formas de vida de esos otros, tal y se puede observar también en el establecimiento de un origen moro de los vaqueiros d'alzada (Cátedra 1989; García Martínez 1988). Así por ejemplo, se recogen testimonios orales sobre los moros como gentes trashumantes que vivían en el monte (Álvarez Peña 2007: 230), en contraposición a las comunidades aldeanas sedentarias que habitarían las laderas más suaves de los valles o sus fértiles vegas.

Uno de los casos más sugerentes es la insistente mención en las narraciones orales del folklore a boleras y juegos de bolos fabricados en oro con los que jugaban los moros que habitaban los castros. Si sustituimos las boleras por los fosos castreños y los elementos de oro por materiales broncíneos como calderos o hachas de talón y anillas, obtendremos una asociación de materiales también reconocida en los niveles prerromanos de los castros. No en vano, en las estructuras liminares de los asentamientos de la Primera Edad del Hierro del occidente cantábrico es frecuente documentar depósitos de materiales metálicos. Cabe citar los ejemplos asturianos de los castros de L.larón (Maya y de Blas 1983) y Alava (Álvarez Martínez et al. 2007b: 20-21). Ante la observación de las huellas dejadas en el terreno por los fosos, es posible pensar que los campesinos expliquen tales trazas constructivas mediante referentes cercanos a su experiencia cotidiana, que encontrarían en las boleras tradicionales asturianas. Las pistas o el rodau de las boleras serían estructuras semejantes a los fosos castreños, mientras que los bolos tienen forma y dimensiones próximas a las hachas de talón y anillas. En las aldeas asturianas no solía faltar una bolera junto al prao de la fiesta. Los juegos tradicionales tenían un importante protagonismo como práctica de socialización en las comunidades rurales, donde los hombres jugaban en días festivos o en el transcurso de fiestas o ferias de ganado.
Es interesante ver cómo los moros, esos seres definidos por su otredad frente a los campesinos, son representados en contextos lúdicos alejados del trabajo agrario. En suma, algunos de estos relatos sobre moros y boleras castreñas reforzarían la referida asociación arqueológica, aportando casos en los que los hallazgos de materiales no habrían trascendido en el ámbito académico y sí habrían dejado huella en la memoria popular (vid. Suárez 2001: 125-134). No obstante, existe el inconveniente de que algunas de estas leyendas hayan podido perder su conexión locacional original y que un relato previo se haya adaptado a una nueva localización formalmente similar a la anterior, lo que limitaría en cierta medida la aplicación de estos referentes en Arqueología. Estos cambios se deben al dinamismo de la transmisión oral del folklore, ya que el narrador puede cambiar localizaciones o datos concretos para dotar de cercanía y actualidad su contenido (Damm 2005: 77-78). A pesar de todo, lo interesante aquí es comprobar cómo ambos ámbitos de conocimiento asumen y traslucen la frecuente deposición de materiales metálicos en relación con las estructuras defensivas de los castros, lo que informaría de ciertas prácticas simbólicas vinculadas a la fundación de nuevos asentamientos (Marín 2009), con buenos ejemplos en El Chao Samartín (Villa y Cabo 2003) y El Picón (Villa 2007a).

Otros casos en la reinterpretación de restos arqueológicos serían los canales que conducían el agua hacia los frentes mineros de las explotaciones auríferas romanas en las que se ponía en práctica el método del ruina montium. Sus características formales responden a la aplicación de avanzados conocimientos ingenieriles propios del Imperio Romano, y totalmente ajenos a la capacidad técnica del campesinado preindustrial, al contar con túneles o adoptar pendientes sostenidas durante decenas de kilómetros (Domergue 1990). Los campesinos explicarán estas estructuras como las trazas de viejos caminos construidos y transitados por los moros, denominándolas de forma genérica como antiguas.

\section{La atención al folklore y a las comunidades locales como fuente de alteridad para la Arqueología castreña}

A pesar de que las aproximaciones arqueológi- 
cas al folklore han llegado a ser vistas como una corriente fringe de la Arqueología (Glazier 2007: 42-43), los arqueólogos han recurrido en numerosas ocasiones -mediante observaciones o encuestas- a los habitantes de los espacios rurales donde investigan para tratar de acercarse a las formas de vida de las gentes del pasado. Los puntos de interés han sido aspectos como el aprovechamiento tradicional y las posibilidades productivas de los distintos espacios agrarios, buscando comprender mejor cómo los grupos prehistóricos asegurarían su subsistencia. Esta línea de atención al paisanaje desde la Arqueología tomó forma, especialmente, con los primeros estudios de la Arqueología espacial. Hoy día, el desarrollo de técnicas como la teledetección ha desplazado en importancia tales herramientas, a la vez que el éxodo rural, el envejecimiento del tejido demográfico y la desestructuración de las formas de vida tradicionales del campo europeo dificultan cada vez más estos estudios etnoarqueológicos.

El diálogo entre los arqueólogos y las comunidades locales no se establecía sobre un marco franco y bidireccional, sino que el flujo informativo tenía un centro gravitatorio claramente controlado desde la Arqueología. Los arqueólogos sólo buscaban obtener y acumular datos, con una participación deficitaria de los campesinos, ya que no recibían ninguna contrapartida en tal proceso comunicativo. Según hemos visto, el marco dialéctico entre las comunidades locales y los investigadores de los castros asturianos puede enmarcarse mayoritariamente en esta clase de relaciones.

Esos primeros acercamientos deberían ser superados, apostando por establecer un nuevo marco de entendimiento más abierto y comprensivo para con las comunidades locales. En vez de extraer datos, los arqueólogos podemos aprender constructivamente de los campesinos, apreciando sus visiones $\mathrm{y}$ formas de relación con el paisaje totalmente ajenas a las categorías presentistas que subyacen a la generación acadénica de conocimientos sobre el pasado. En este momento de auge de la sofisticación, tecnificación y especialización de nuestra disciplina, con la proliferación de complejos métodos de trabajo derivados de "ciencias duras" como la Genética, la Física, la Química, la Geología, la Estadística... la atención al paisanaje y al folklore puede ser un excepcional catalizador de nuestras interpretaciones sobre las comunidades castreñas que nos ayude a contrarrestrar el peso de los apor- tes mecánicos y normativos de las mencionadas contribuciones interdisciplinares, ganando así en reflexividad (Hodder 2003: 57-58). Por muy técnico que pueda volverse nuestro trabajo cotidiano como arqueólogos, no debemos olvidar nuestro papel de historiadores y científicos sociales.

Las narraciones orales del folklore son importantes para el sostenimiento de los esquemas identitarios del campesinado y la preservación de su dignidad. Estos ricos constructos cosmográficos se encuentran actualmente en crisis frente al avance imparable de la globalización, cuya uniformización del pensamiento y las formas de entender el mundo, además de afectar a países lejanos, se deja sentir de forma palpable en el medio rural occidental (González Ruibal 2003a, 2008). Ante esta devastadora situación, los arqueólogos podríamos ayudar a que las comunidades rurales europeas revalorizasen la oralidad. Los relatos del folklore con temática arqueológica dejarían de ser vistos como historietas fantásticas o "cuentos de viejos" para pasar a ser considerados como el reflejo de una determinada forma de entender y relacionarse con el mundo.

Romper con la Arqueología del nosotros nos enfrenta con cuestiones relacionadas con diferentes formas de documentar, reconstruir y presentar el pasado de los grupos subalternos (Damm 2005: 73), lo que ayudará a romper con el etnocentrismo y el presentismo imperantes en los estudios arqueológicos tradicionales. En las últimas décadas, las Arqueologías críticas han tratado de señalar los prejuicios etnocéntricos, androcéntricos, evolucionistas, coloniales o presentistas de nuestra disciplina, pues frecuentemente contribuyen a naturalizar discursos de poder que mantienen subyugadas a los grupos subalternos mediante su proyección hacia el pasado (Fernández Martínez 2006), aunque pocas veces se insiste en sus prejuicios urbanitas. Prestar atención al pensamiento de las grupos preindustriales arrinconados en el medio rural de los estados occidentales contemporáneos nos ayudará a superar las imposiciones mecanicistas y maximizadoras de nuestro pensamiento capitalista y urbano, en cuanto al aprovechamiento productivo del entorno u otras prácticas vitales elementales. Así por ejemplo, podremos tomar conciencia de la inexistente o mínima separación entre lo ritual y lo mundano; incluso en contextos o actividades propias de la vida cotidiana (Gazin-Schwartz 2001: 278), superando las visio- 
nes tradicionales sobre el papel de lo ritual en las comunidades prehistóricas (Renfrew 1994). No se trata tanto de contemplar las prácticas de los habitantes del medio rural como continuidades desde la Edad del Hierro (vid. Torres y Sagardoy 2006), como de entender que las estructuras de pensamiento elaboradas en clave mítica por los campesinos difieren completamente de las nuestras. Piensan diferente a nosotros y, por tanto, construyen y viven en paisajes simbólicos muy distintos a los nuestros. Su visión del mundo será más cercana a la de las gentes prehistóricas que la nuestra, como investigadores urbanos del presente. Si desde nuestra actual perspectiva empirista nosotros podemos ver árboles, arroyos o montañas, los campesinos pueden vislumbrar múltiples manifestaciones sobrenaturales (vid. Gazin-Schwartz 2001: 273-274) que también perciben en yacimientos o en materiales pretéritos, como las piedras de rayu.

A pesar de esto, es importante evitar el establecimiento de primacías entre las distintas voces que se aproximan a yacimientos como los castros asturianos. La posibilidad de que se construyan múltiples lecturas alrededor de estos enclaves, con diferentes interpretaciones de unas mismas evidencias, ha de ser garantizada mediante el establecimiento de un diálogo franco y abierto con las comunidades locales en el transcurso de las prácticas arqueológicas (Atalay 2008: 34). Cada relato oral tiene sentido en un determinado marco de pensamiento, por lo que se debería evitar que los condicionantes del empirismo arqueológico puedan imponerse sobre los componentes míticos y vivenciales de las tradiciones locales (Atalay 2008: 43; Damm 2005: 84). No obstante, los excesos en la búsqueda y sostén de la multivocalidad tienen riesgos que pueden socavar la solidez de los resultados finales de nuestro trabajo en términos de objetividad. Debemos recordar que las comunidades locales no siempre tienen puntos de vista prístinos o acertados, sino que existen aspectos de su pensamiento que pueden ser contraproducentes a la hora de valorar determinados aspectos o testimonios materiales (Hodder 2008: 199).

La mejor ocasión para establecer el diálogo con las comunidades locales se da en el transcurso de los trabajos arqueológicos de campo, dentro de su paisaje cotidiano. Es entonces cuando el destructivo método arqueológico desconecta a los objetos de su localización original, muchas veces imbuida de una fuerte carga simbólica para las poblaciones locales (Hodder 2003: 59). Al pretender involucrarles en nuestras actividades, no hablo sólo de incorporar personal contratado entre las comunidades locales a las tareas arqueológicas, pues en la mayoría de las ocasiones se acaban generando dicotomías jerárquicas y segregaciones entre las labores intelectuales y manuales, desarrolladas por arqueólogos o estudiantes y trabajadores locales, respectivamente (vid. Hamilakis y Anagnostopoulos 2009: 80). Debemos apostar por relacionarnos con los grupos locales de igual a igual, asumiendo que manejamos diferentes construcciones intelectuales acerca de un objeto de atención común: el paisaje, los monumentos naturales, los yacimientos... Con la transmisión de los resultados de nuestro trabajo, podríamos ofrecerles relatos alternativos que complementasen sus propios discursos, enfatizando la idea de que las narraciones del folklore son discursos estructuralmente tan válidos como los arqueológicos para sus respectivos relatores y consumidores. Como hemos visto aquí, ambos coinciden en la importancia otorgada a determinados hitos paisajísticos. La transmisión de esta idea propiciaría un mayor interés de las poblaciones locales por las narraciones orales y los elementos patrimoniales: por su preservación, su conocimiento y su difusión.

\section{Conclusiones}

Hoy día sigue siendo posible escuchar relatos de la tradición oral campesina en boca de los habitantes del medio rural asturiano. En conjunto, forman un corpus informativo de gran interés que se encuentra en una situación crítica en cuanto a su conservación en un contexto vivo. A pesar de que se haya dicho que el folklore sólo es tal cuando es contado y escuchado (Glazier 2007: 45), es verdaderamente acuciante emprender un último esfuerzo en la recogida y estudio, desde todas las perspectivas posibles, de este Patrimonio cultural inmaterial, pues va a desaparecer irremediablemente a lo largo de este recién estrenado siglo XXI.

Los castros tuvieron un sentido y un contexto humano posterior a su abandono al que la Arqueología puede aproximarse. Las comunidades preindustriales que cohabitaron con sus ruinas en lo sucesivo incorporaron tales enclaves al contenido narrativo de su memoria colectiva. Con esta perspectiva, las leyendas del folklore campesino 
asturiano relacionadas con estos yacimientos pueden tomarse como antecedentes en la generación de relatos interpretativos sobre la Edad del Hierro.

La investigación castreña asturiana ha tomado en consideración el folklore con distintas ópticas a lo largo de su trayectoria. El diálogo se ha establecido mayoritariamente con cierta prepotencia desde el plano académico, incluso despreciando explícitamente las tradiciones orales de las comunidades locales, tachándolas de atrasadas e ignorantes. Sobre este fondo oscuro destacan, para su tiempo, autores como Aurelio del Llano o José Manuel González, quienes rompieron con la ceguera o desprecio que mostraban los primeros estudios castreños hacia tales formas discursivas. Entre los motivos de ese generalizado desdén inicial, podemos aludir a los prejuicios de los investigadores de procedencia urbana y de clase acomodada. Destaca por contra el origen rural de los autores arriba citados, más atentos y sensibles a la memoria oral campesina. Tras la consolidación académica de la Arqueología, el creciente tinte procesualista imperante en los estudios castreños asturianos de finales del siglo XX ha hecho que las alusiones al folklore sean siempre anecdóticas o que sólo sean tomadas en consideración en tareas prospectivas. No obstante, existen excepciones, ya referidas, que arrojan un rayo de luz a futuras tentativas que relacionen folklore y Arqueología.

El folklore no es un corpus de leyendas fantasiosas. Es una parte singularmente visible de la estructura de pensamiento relacional propia de las comunidades preindustriales. El primer paso en nuestro acercamiento al folklore será necesariamente comprender y tener en cuenta su sentido emic en las estructuras cosmológicas de los campesinos, para poder así aproximarnos al significado real de estos relatos en su propio contexto vivencial. Esta cosmología tradicional es local y contextual, con lo que las generalizaciones de algún componente puntual hacia ámbitos humanos, geográficos o cronológicos más amplios de los que en realidad abarque tal elemento narrativo no son recomendables. Debemos asumir por tanto que no podremos establecer analogías rígidas para tomar datos o informaciones directamente del folklore y llevarlas a las reconstrucciones histórico-arqueológicas del pasado. Sólo después de comprender estos preceptos será honesto tratar de emplear en Arqueología contenidos del folklore de comunidades preindustriales como las del medio rural asturiano.
Es posible identificar elementos castreños en muchas narraciones orales del campesinado asturiano. Esto puede ayudar a los arqueólogos en tareas prospectivas y en la valoración de datos arqueológicos observados al margen de la academia. Sin embargo, la atención al folklore puede ser útil más allá de los relatos surgidos alrededor del hallazgo de materiales singulares (Herva y Ylimaunu 2009: 242). Este diálogo interdisciplinar puede enriquecer la biografía de objetos arqueológicos o lugares con ocupaciones antiguas (Barrowclough y Hallam 2008: 100), aclarando los tiempos de las distintas narraciones recogidas en el folklore. Aporta también informaciones sobre los procesos históricos que originaron algunas leyendas, ayudando a comprender mejor los mecanismos de funcionamiento de la oralidad. Como especialistas de la materialidad, nos situamos en una posición privilegiada para desentrañar los mecanismos por los que los mitos del folklore se engarzan y vinculan a determinados enclaves. Narraciones orales y lugares $u$ objetos materiales se refuerzan mutuamente para consolidar su vigencia en la memoria de las comunidades preindustriales. Esta situación se evidencia en la investigación arqueológica de los castros asturianos, ya que la ligazón entre los relatos orales y las ruinas de los pretéritos poblados de la Edad del Hierro ha facilitado, en muchos casos, desde su correcta identificación hasta la obtención de informaciones y descripciones relativas a elementos materiales muebles vinculados con el poblado o a su disposición constructiva.

La aproximación que los arqueólogos podemos hacer al poblamiento de la Edad del Hierro no deja de ser un acercamiento parcial a la más breve etapa de la biografía de los enclaves castreños. Una vez abandonados por los grupos prehistóricos que los construyeron, los castros han seguido vivos en el imaginario colectivo del campesinado, más allá de su presencia en los libros de Historia, en los museos o en las paredes de las casas aldeanas, construidas en ocasiones con piedras extraídas de las ruinas castreñas. Son verdaderos lugares de memoria, hogar de seres fantásticos y soporte de leyendas que contribuyen a apuntalar la cosmografía de las sociedades preindustriales. Son hitos destacados en la construcción y sostén de su propia identidad. La reiterada presencia de las ruinas y los objetos castreños en el contenido narrativo del folklore campesino puede ser vista como la necesaria presencia del otro que, por oposición, refuerza la lógica 
social e identitaria de las comunidades aldeanas del medio rural asturiano. Incluso los arqueólogos nos convertimos en referencias de otredad para las comunidades locales, al relacionarnos insistentemente con estos espacios cargados de simbolismo (sensu Hamilakis y Anagnostopoulos 2009: 74).

Los campesinos generan discursos legitimadores de sus formas sociales e identitarias empleando los castros como ejes de narrativas tan importantes para ellos como las que definen la otredad. Podemos así calibrar la importancia que las comunidades castreñas podían otorgar a la selección de esas mismas localizaciones como sus espacios de hábitat, con ubicaciones bien definidas topográfica y paisajísticamente, y con relaciones constatadas entre algunos castros y monumentos previos a la Edad del Hierro, como megalitos, arte esquemático u otros hitos naturales.

La atención a los relatos del folklore ofrece una gran potencia inspiradora como aliento de la interpretación arqueológica. El pensamiento mítico funciona mediante operaciones y categorizaciones intelectuales bien diferentes al empirismo que estructura la cosmografía de la sociedad capitalista actual. Con el establecimiento de una cierta comunicación entre Arqueología y folklore, los arqueólogos estableceremos una visión más crítica y comprensiva con la que crear imágenes alternativas sobre las gentes de tiempos pretéritos (GazinSchwartz y Holtorf 1999b: 3), tras atender a las divergencias y coincidencias entre las interpretaciones que ambas aproximaciones dan de los yacimientos arqueológicos.
Los arqueólogos nos podemos acercar al pensamiento preindustrial contenido en el folklore con bastante dificultad, asumiendo que nuestras aproximaciones descansarán necesariamente sobre operaciones interpretativas: nunca reconstructivas o explicadoras. La forma de entender las narraciones orales del folklore por los campesinos tradicionales tiene una perspectiva enteramente emic, mientras que la Arqueología plantea lecturas del pasado en clave etic. Por ello, si prestamos atención de forma comprensiva y honesta a los relatos del folklore, podremos establecer valiosos puntos de apoyo gracias a los cuales nuestras interpretaciones arqueológicas e históricas ascenderán en cotas de alteridad. Pero tampoco debemos sobrevalorar la importancia, legitimidad o autenticidad de los relatos orales y de las voces locales. Como arqueólogos, componemos nuestro propio discurso científico, por lo que no debemos ser ajenos a los mínimos valores epistemológicos y metodológicos de nuestra disciplina. Por muy reflexiva e interdisciplinar que sea nuestra investigación, no debemos perder de vista que la cultura material deberá situarse como el elemento central sobre el que pivotarán nuestras interpretaciones arqueológicas.

Es importante realizar un verdadero esfuerzo por acercar nuestro trabajo a las comunidades locales, para quienes nuestra principal aportación podría ser la revalorización de su memoria oral como discurso válido relacionado con los yacimientos arqueológicos, ya que son relatos coherentes con su pensamiento y cumplen para ellos una función básica en la definición de su identidad.

\section{Agradecimientos}

Debo agradecer la ayuda prestada por diferentes personas durante la preparación de este trabajo. Armando Graña ha sido un catalizador clave en mi interés por el paisanaje del medio rural asturiano. Andrés Menéndez me introdujo en la práctica de la encuesta oral y tuvo la amabilidad de facilitarme algunas transcripciones fruto de su trabajo de campo. Carlos Marín realizó una lectura crítica de un primer borrador de este texto que resultó muy estimulante para la configuración definitiva del trabajo. Los comentarios y valoraciones de los/as evaluadores/as anónimos/as y del comité de redacción de la revista contribuyeron a reforzar y clarificar el texto final. 


\section{REFERENCIAS BIBLIOGRÁFICAS}

Álvarez Martínez, V.; Expósito Mangas, D.; GonzÁlez Álvarez, D. (2007a): El cementerio moro de Barcia: Breve acercamiento a su estudio. Actas del I Congreso de Estudios Asturianos, Tomo V (Comisión de Artes, Arquitectura y Urbanismo), RIDEA, Oviedo: 131-150.

Álvarez Martínez, V.; Expósito Mangas, D.; González Álvarez, D. (2007b): Los castros del concejo de Salas. Salas en el Camino, 3: 16-26.

Álvarez Peña, A. (2002): El castru de la Punta'1 Castiello. Podes (Gozón). Asturies: memoria encesa d'un país, 13: 20-24.

Álvarez Peña, A. (2007): Arqueología y tradición oral asturiana. Estudios Varios de Arqueología castreña. A propósito de las excavaciones en los castros de Teverga (Asturias) (A. Fanjul Peraza, ed.), Ayto.TevergaI.E.P.A., Teverga: 225-235.

Aparicio CASADO, B. (1999): Mouras, serpientes, tesoros y otros encantos. Mitología popular gallega. Ediciós do Castro, Cadernos do Seminario de Sargadelos, 80, Sada, A Coruña.

ARIas y CAunedo, J. (1884): Breve revista de Teverga y Somiedo. Contiene la tradición, cuevas y lagos famosos, Minerales, montes y paisajes agrestes, Fiestas de campo de estos concejos con un breve extracto de la vida de algunos hombres que en estos términos han merecido concepto de celebridad. Imprenta de Ramiro Pérez del Río, Luarca.

Arizaga Castro, A.R.; Ayán VILA, X.M. (2005): Os Castros de Neixón como espazo simbólico na paisaxe rural tradicional (notas etnográficas e reflexións sociais). Os Castros de Neixón, Boiro, A Coruña (X.M. Ayán Vila, ed.), Toxosoutos, Noia: 291-327.

Arizaga Castro, A.R.; Ayán Vila, X.M. (2007): Etnoarqueología del paisaje castreño: La segunda vida de los castros. Los pueblos de la Galicia céltica (J.M. González García, ed.), Akal, Madrid: 445-531.

AtALAY, S. (2008): Multivocality and Indigenous Archaeologies. Evaluating Multiple Narratives: Beyond Nationalist, Colonialist, Imperialist Archaeologies (J. Habu, C. Fawcett y J.M. Matsunaga eds.), Springer, New York: 29-44.

AYÁn VILA, X.M. (2005): Os castros despois dos castros: Un espazo simbólico na paisaxe rural tradicional galega. Encontros coa Etnografia (P. Ballesteros, ed.), Toxosoutos, Noia: 63-136.

Barrowclough, D.A.; Hallam, J. (2008): The Devil's Footprints and Other Folklore: Local Legend and Archaeological Evidence in Lancashire. Folklore, 119: 93-102.

BARTRA, R. (1996): El salvaje en el espejo. Destino, Barcelona.

Berrocal-Rangel, L.; Martínez Seco, P.; Ruiz Triviño, C. (2002): El Castiellu de Llagú (Latores, Oviedo). Un castro astur en los orígenes de Oviedo. RAH, Madrid.

BIELAWSKI, E. (1994): Dual perceptions of the past: archaeology and Inuit culture. Conflict in the Archaeology of Living Traditions (R. Layton, ed.), Routledge, London: 228-236.

Blas Cortina, M.A. DE (1974-1975): Los grabados rupestres del Picu Berrubia. Ampurias, 36-37: 63-86.

Blas Cortina, M.A. de (1977): Notas sobre el conjunto tumular de el valle, Cabruñana (Grado). Boletín del Instituto de Estudios Asturianos, 93-94: 323-333.

Blas Cortina, M.A. de (1983): La Prehistoria Reciente en Asturias. Fundación Pública de Cuevas y Yacimientos Prehistóricos de Asturias, Oviedo.

Blas Cortina, M.A. de; López Álvarez, J. (2001): Sobre la búsqueda tradicional de oro en yacimientos arqueológicos y la noticia de un probable tesoro prehistórico en tierras de Grao en el siglo XVI. Ástura, Nuevos cortafueyos d'Asturies, 11: 9-16.

Blas Cortina, M.A. de; Maya González, J.L. (1974): Hachas pulimentadas en castros asturianos. Boletín del Instituto de Estudios Asturianos, 81: 199-216.

Blas Cortina, M.A. de; Villa Valdés, A. (2008): El ciclo terminal de la Edad del Bronce y las raíces de la Cultura Castreña. La Prehistoria en Asturias. Un legado artístico único en el mundo (J. Rodríguez Muñoz, ed.), Ed. Prensa Asturiana, Oviedo: 659-672.

BouZA Brey, F. (1963): Noticias históricas de la villa de La Caridad y otras cédulas arqueológicas del occidente. Boletín del Instituto de Estudios Asturianos, 48: 46-49.

BradLey, R. (2002): The Past in Prehistoric Societies. Routledge, London.

CAMINo MaYor, J. (1995): Los castros marítimos en Asturias. RIDEA, Oviedo.

CAmino Mayor, J. (1997): Excavaciones en los castros de la ría de Villaviciosa. Cuadernos de Cubera, 9: 43-86.

CAmino Mayor, J. (2003): Los castros de la Ría de Villaviciosa: contribución a las interpretaciones de la Edad del Hierro en Asturias. Trabajos de Prehistoria, 60(1): 159-171.

Camino Mayor, J.; Estrada García, R.; Viniegra Pacheco, Y. (2009): El castro inacabado de La Forca (Grado, Asturias). Un dominio territorial frustrado. Trabajos de Prehistoria, 66(1): 145-159. 
Carrocera Fernández, E. (1990): El castro de San Isidro: informe de las excavaciones arqueológicas 1986. Excavaciones Arqueológicas en Asturias, 1: 157-162.

CARrocera Fernández, E. (1992): Excavaciones arqueológicas en el occidente de Asturias (Campañas de 19871990). Excavaciones Arqueológicas en Asturias, 2: 129-136.

Carrocera Fernández, E. (1994): Estudio crítico de la cultura castreña asturiana. Trabalhos de Antropologia e Etnologia, 34(3-4): 213-221.

Caso Blanco, E. (2007): Prospección en el valle del Piloña-2002. Zona Infiestu-Villamayor. Excavaciones Arqueológicas en Asturias, 5: 471-476.

Castañeda, Q.; Matthews, C.N. (eds.) (2008): Ethnographic Archaeologies. Reflections on Stakeholders and Archaeological Practices. AltaMira Press, Plymouth.

CÁtedra TomÁs, M. (1989): La vida y el mundo de los vaqueiros de alzada. CIS, Madrid.

Collis, J.R. (2003): The Celts. Origins, Myths and Inventions. Tempus, Stroud.

DAmM, C. (2005): Archaeology, Ethno-history and Oral Traditions: Approaches to the Indigenous Past. Norwegian Archaeological Review, 38(2): 73-87.

Díaz-Andreu, M.; Lucy, S.; Babic, S.; Edwards, D.N. (2005): The Archaeology of Identity. Approaches to gender, age, status, ethnicity and religion. Routledge, London.

DoDs, R.R. (2004): Knowing ways/ways of knowing: reconciling science and tradition. World Archaeology, 36(4): 547-557.

Domergue, C. (1990): Les mines de la Péninsule Ibérique dans l'Antiquité romaine. École Françoaise de Rome, Roma.

EchO-HAwK, R.C. (2000): Ancient History in the New World: Integrating Oral Traditions and the Archaeological record in deep time. American Antiquity, 65(2): 267-290.

Fanjul Peraza, A. (2005): Los castros de Asturias. Una revisión territorial y funcional. Ayto.Teverga, Teverga.

Fanjul Peraza, A.; Fernández Rodríguez, C.; LóPez Pérez, M.C.; Álvarez Peña, A. (2009): Excavaciones en los castros de La Cogollina y La Garba (Teverga). Pautas del poblamiento castreño en un valle de montaña. Excavaciones Arqueológicas en Asturias, 6: 465-472.

Fernández Buelta, J.M. (1949): Castro de La Escrita o Ríu de Castro-Boal. Boletín del Instituto de Estudios Asturianos, 8: 121-127.

FernÁndez Buelta, J.M. (1950): Castro de Arancedo. Boletín del Instituto de Estudios Asturianos, 10: 179-190.

FernÁndez Conde, F.J. (2000): La religiosidad medieval en España I, Alta Edad Media (s. VII-X). Universidad de Oviedo, Oviedo.

FernÁNDEZ De Rota, J.A. (1984): Antropología de un viejo paisaje gallego. CIS/Siglo XXI, Madrid.

FERNÁNDEZ MARTíNEZ, V.M. (2006): Arqueologías críticas: El conflicto entre verdad y valor. Complutum, 17: $191-203$.

FernÁNDEZ Mier, M. (1999): Génesis del territorio en la Edad Media. Arqueología del paisaje y evolución histórica en la montaña asturiana. Universidad de Oviedo, Oviedo.

Flórez y GonZÁlez, J.M. (1878): Memoria relativa a las excavaciones de El Castellón en el concejo de Coaña (Asturias). Imprenta y Lit. de Vicente Brid, Oviedo.

Forbes, H. (2009): Researching Ekina ta Khronia [Times Past] in a Rural Greek Community. Public Archaeology, 8(2-3): 88-107.

GARCíA Fernández, J. (1980): Sociedad y organización tradicional del espacio en Asturias. Silverio Cañada Editor, Gijón.

García Martínez, A. (1988): Los vaqueiros de alzada de Asturias. Un estudio histórico-antropológico. Principado de Asturias, Oviedo.

García Martínez, A. (2008): Antropología de Asturias I. La cultura tradicional, Patrimonio de futuro. KRK, Oviedo.

García Vuelta, O. (2001): El conjunto de Cangas de Onís: Arqueología del oro castreño asturiano. Trabajos de Prehistoria, 58(2): 109-127.

GARCíA Y Bellido, A. (1941): El castro de Coaña (Asturias) y algunas notas sobre el posible origen de esta cultura. Archivo Español de Arqueología, 14(42): 188-217.

García y Bellido, A. (1942a): El castro de Coaña (Asturias). Nuevas aportaciones. Archivo Español de Arqueología, 15(48): 216-244.

García y Bellido, A. (1942b): El castro de Pendia. Archivo Español de Arqueología, 15(49): 288-305.

GAZIN-Schwartz, A. (2001): Archaeology and Folklore of Material Culture, Ritual, and Everyday Life. International Journal of Historical Archaeology, 5(4): 263-280.

Gazin-Schwartz, A.; Holtorf, C. (eds.) (1999a): Archaeology and Folklore. Routledge, Londres.

Gazin-Schwartz, A.; Holtorf, C. (1999b): As long as ever I've know it... Archaeology and Folklore (A. GazinSchwartz y C. Holtorf eds.), Routledge, London: 3-25. 
GLAzIER, D. (2007): Telling Tales: Folklore, Archaeology and the Discovery of the Past in the Present. Which Past, Whose Future? Treatments of the Past at the Start of the 21 st Century (S. Grabow, D. Hull y E. Waterton eds.), Archaeopress, BAR Int. Series 1633, Oxford: 41-49.

GonzÁlez-Quevedo, R. (2002): Antropología social y cultural de Asturias: introducción a la cultura asturiana. Ed. Madú, Granda (Siero).

GonzÁlez Álvarez, D. (2008): Etnoarqueología del paisanaje tradicional como fuente de información en Arqueología. Actas de las I Jornadas de Jóvenes en Investigación Arqueológica: Dialogando con la cultura material (JIA 2008), Tomo I (Orjia, ed.), CERSA, Madrid: 237-244.

GonzÁlez Reboredo, J.M. (1971): El Folklore en los castros gallegos. Universidad de Santiago de Compostela, Santiago de Compostela.

González Ruibal, A. (2003a): Etnoarqueología de la emigración. El fin del mundo preindustrial en Terra de Montes (Galicia). Diputación de Pontevedra, Pontevedra.

GonzÁlez Ruibal, A. (2003b): La experiencia del otro. Una introducción a la Etnoarqueología. Akal, Madrid.

GonzÁlez Ruibal, A. (2006-2007): Galaicos: Poder y Comunidad en el Noroeste de la Península Ibérica (1200 a.C. - 50 d.C.). Museo de San Antón, Brigantium, 18-19, A Coruña.

GonzÁlez Ruibal, A. (2008): Time to destroy. An archaeology of supermodernity. Current Anthropology, 49(2): 247279.

GonZÁlez y FernÁNDEZ-VAllÉs, J.M. (1958): Monsacro y sus tradiciones. Archivum, 8: 48-81.

GonZÁlez y FernÁNDEZ-VALLÉs, J.M. (1966): Catálogo de los castros asturianos. Archivum, 16: 255-291.

GonZÁlez y FernÁNDEZ-VAllés, J.M. (1973): Castros asturianos del sector lucense y otros no catalogados. Cuadernos de Estudios Gallegos, 28.

GonzÁlez y FernÁndez-Vallés, J.M. (1978): Historia de Asturias. Vol.2, Asturias protohistórica. Ayalga, Salinas.

GonzÁlez y Fernández-VAllés, J.M.; Manzanares Rodríguez, J. (1959): Arracada áurea del Castello de Berducedo. Boletín de la Comisión Provincial de Monumentos, 2: 23-32.

Gutiérrez GonzÁlez, J.A. (1996): El Páramo Leonés entre la Antigüedad y la Alta Edad Media. Studia historica. Historia medieval, 14: 47-96.

Gutiérrez GonzÁlez, J.A. (2002): Del Castrum al Castellum. Los castros entre la Antigüedad y la Edad Media. Los poblados fortificados del noroeste de la Península Ibérica: formación y desarrollo de la Cultura Castreña (M.A. de Blas y A. Villa eds.), Ayto.Navia, Navia: 301-316.

Hamilakis, Y.; Anagnostopoulos, A. (2009): What is Archaeological Ethnography? Public Archaeology, 8(2-3): 6587.

Hernando Gonzalo, A. (1999): El espacio no es necesariamente un lugar: en torno al concepto de espacio y a sus implicaciones en el estudio de la Prehistoria. Arqueología Espacial, 21: 7-27.

Hernando Gonzalo, A. (2002): Arqueología de la Identidad. Akal, Madrid.

Hernando Gonzalo, A. (2006): Arqueología y Globalización. El problema de la definición del otro en la Postmodernidad. Complutum, 17: 221-234.

Herva, V.-P. (2009): Living (with) Things: Relational Ontology and Material Culture in Early Modern Northern Finland. Cambridge Archaeological Journal, 19(3): 388-397.

Herva, V.-P.; Ylimaunu, T. (2009): Folk beliefs, special deposits, and engagement with the enviroment in early modern northern Finland. Journal of Anthropological Archaeology, 28: 234-243.

Hevia Llavona, N. (1997): Un nuevu hachu neolíticu atopáu n'Asturies: l'hachu de L'Arbeyal y les piedres del rayu. Asturies: memoria encesa d'un pais, 4: 36-39.

Hingley, R. (1996): Ancestors and identity in the later prehistory of Atlantic Scotland: the reuse and invention of Neolithic monuments and material culture. World Archaeology, 28(2): 231-243.

HodDER, I. (2003): Archaeological Reflexivity and the "Local" Voice. Anthropological Quarterly, 76(1): 55-69.

HodDer, I. (2008): Multivocality and Social Archaeology. Evaluating Multiple Narratives. Beyond Nationalist, Colonialist, Imperialist Archaeologies (J. Habu, C. Fawcett y J.M. Matsunaga eds.), Springer, New York: 196200.

Holtorf, C. (2005): From Stonehenge to Las Vegas. Archaeology as Popular Culture. Altamira Press, Walnut Creek.

Hrobat, K. (2007): Use of Oral Tradition in Archaeology: the case of Ajdovšcina above Rodik, Slovenia. European Journal of Archaeology, 10(1): 31-56.

Jordá Cerdá, F.; Manzano Hernández, M.P.; Jordá Pardo, J.F.; González-Tablas Sastre, F.J.; Carrocera Fernández, E.; BÉCARes PÉrez, J. (1989): El castro asturiano de San Chuis. Revista de Arqueología, 95: 38-58.

JordÁ PARDO, J.F. (2009): Descubriendo el castro de San Chuis (Allande, Asturias): nuevas aportaciones al conocimiento de la cronología radiocarbónica de los castros asturianos. Arqueología castreña en Asturias (C. Marín Suárez y J.F. Jordá Pardo eds.), UNED, Centro Asociado de Asturias, Entemu 16, Gijón: 47-63. 
Labandera Campoamor, J.A. (1969a): Castros de Occidente. Primer avance. Boletín del Instituto de Estudios Asturianos, 66: 61-83.

LABANDERA CAMPOAMOR, J.A. (1969b): Identificación y estudio del castro del Esteiro. Boletín del Instituto de Estudios Asturianos, 68: 475-496.

Labandera Campoamor, J.A. (1970): Cultura de los Castros. Boletín del Instituto de Estudios Asturianos, 60: 105124.

LABANDERA CAMPOAmor, J.A. (1974): Castro del Toxal y origen de Tapia. Boletín del Instituto de Estudios Asturianos, 81: $185-198$.

LANE, P. (2006): Oral Histories and Indigenous Archaeology: An Africanist Perspective. Comments on Charlotte Damm (2005): Archaeology, Ethnohistory and Oral Traditions: Approaches to the Indigenous Past. Norwegian Archaeological Review 38, 73-87. Norwegian Archaeological Review, 39(1): 70-73.

LaYton, R. (1999): Folklore and world view. Archaeology and Folklore (A. Gazin-Schwartz y C. Holtorf eds.), Routledge, Londres: 26-34.

Lisón Tolosana, C. (1977): Antropología Cultural de Galicia. Moradas del vivir galaico. Siglo XXI, Madrid.

Llano Roza de Ampudia y de Valle, A. (1919): El libro de Caravia. Imprenta Gutenberg, Oviedo.

Llinares García, M. (1990): Mouros, ánimas, demonios. El imaginario popular gallego. Akal, Madrid.

López GonzÁlez, L.F.; Álvarez GonzÁlez, Y.; López Marcos, M.A. (1999): Excavación en el castro de Llagú, Latores (Oviedo 1998). Avance de los resultados. Excavaciones Arqueológicas en Asturias, 4: 237-251.

Marín SuÁrez, C. (2004): Historiografía de la Edad del Hierro en Asturias. Complutum, 15: 75-97.

Marín SuÁrez, C. (2005a): Astures y asturianos. Historiografía de la Edad del Hierro en Asturias. Toxosoutos, Noia.

Marín SuÁreZ, C. (2005b): El celtismo asturiano. Una perspectiva arqueológica. Gallaecia, 24: 309-333.

Marín SuÁrez, C. (2009): De nómadas a castreños. Los orígenes de la Edad del Hierro en Asturias. Arqueología castreña en Asturias (C. Marín Suárez y J.F. Jordá Pardo eds.), UNED, Centro Asociado de Asturias, Entemu 16, Gijón: 21-46.

Martínez Fernández, J. (1970): Castro de Mohías. Nuevos hallazgos y descubrimientos. Boletín del Instituto de Estudios Asturianos, 69: 125-140.

Martínez Fernández, J.; Junceda Avello, J.M. (1968): Descubrimiento del castro de Mohías. Primeras excavaciones y primeros hallazgos. Boletín del Instituto de Estudios Asturianos, 63: 185-199.

Mason, R.J. (2000): Archaeology and Native North American Oral Traditions. American Antiquity, 65(2): $239-266$.

Maya GonZÁlez, J.L. (1989): Los castros en Asturias. Silverio Cañada Editor, Gijón.

Maya González, J.L.; Blas Cortina, M.A. De (1983): El castro de Larón (Cangas del Narcea, Asturias). Noticiario Arqueológico Hispánico, 15: 153-192.

Maya GonzÁlez, J.L.; Cuesta Toribio, F. (2001): El castro de La Campa Torres. Período prerromano. VTP editorial, Gijón.

Moore, S. (2008): Myths and folklore as aids in interpreting the prehistoric landscape at the Carrowkeel passage tomb complex, Co. Sligo, Ireland. Folk Beliefs and Practice in Medieval Lives (A.B. Falk y D.M. Kyritz eds.), Archaeopress, BAR Int. Series 1757, Oxford: 7-21.

PinA-CABral, J. (1989): The valuation of time among the peasant population of the Alto Minho, northwestern Portugal. Who Needs the Past? Indigenous values and archaeology (R. Layton, ed.), Routledge, Londres: 5969.

PIngel, V. (1992): Die vorgeschichtlichen Goldfunde der Iberischen Halbinsel. Eine archäeologische Untersuchung zur Auswertung der Spektranalysen. Deutsches Archäologisches Institut. Madrider Forschungen, Band 17. Walter de Gruyter und Co. Berlín.

RENFrew, C. (1994): The archaeology of religion. The Ancient Mind: Elements of Cognitive Archaeology (C. Renfrew y E. Zubrow eds.), Cambridge University Press, Cambridge: 47-54.

Rivas Rivas, A.M. (1991): Antropología Social de Cantabria. Universidad de Cantabria, Santander.

Rowlands, M.J. (1993): The role of memory in the transmission of culture. World Archaeology, 25(2): 141-151.

SANTOS Granero, F. (1998): Writing history into the Landscape: Space, myth, and ritual in contemporany Amazonia. American Ethnologist, 25(2): 128-148.

SuÁrez López, J. (2001): Tesoros, Ayalgas y Chalgueiros. La fiebre del oro en Asturias. Museo del Pueblo de Asturias, Gijón.

Thompson, T. (2004): The Irish Sí Tradition: Connections Between the Disciplines, and What's in a Word. Journal of Archaeological Method and Theory, 11(4): 335-368.

Torres Martínez, J.F.; SAgardoy Fidalgo, T. (2006): La etnoarqueología en el norte de la Península Ibérica y el estudio de las sociedades protohistóricas. Etnoarqueología de la Prehistoria: más allá de la analogía, Institució Milà i Fontanals, Barcelona: 95-108. 
Vega del Sella, R. (1919): El dolmen de la capilla de Santa Cruz (Asturias). Museo Nacional de Ciencias Naturales, Madrid.

Villa VAldÉs, A. (2002): Sobre la secuencia cronoestratigráfica de los castros asturianos (siglos VIII a.C.-II d.C.). Trabajos de Prehistoria, 29(2): 149-162.

Villa Valdés, A. (2005): El castro de Chao Samartín Samartín. Guía para su interpretación y visita. Sociedad Arqueológica Profesional, Oviedo.

Villa VAldÉs, A. (2007a): El castro de El Picón (La Coroza, Tapia de Casariego): un poblado de la Edad del Bronce en la marina occidental asturiana. Excavaciones Arqueológicas en Asturias, 5: 277-282.

Villa ValdÉs, A. (2007b): Mil años de poblados fortificados en Asturias (siglos IX a.C.-II d.C.). Astures y romanos: nuevas perspectivas (J.A. Fernández-Tresguerres, ed.), RIDEA, Oviedo: 27-60.

Villa VAldÉs, A. (2008): Las transformaciones del paisaje castreño en época romana. La Prehistoria en Asturias. Un legado artístico único en el mundo (J. Rodríguez Muñoz, ed.), Ed. Prensa Asturiana, Oviedo: 801-816.

Villa VAldÉs, A.; CABo PÉREZ, L. (2003): Depósito funerario y recinto fortificado de la Edad del Bronce en el castro del Chao Samartín: argumentos para su datación. Trabajos de Prehistoria, 60(2): 143-151.

Viveiros de CASTRO, E. (1996): Os pronomes cosmológicos e o perspectivismo ameríndio. Mana, 2(2): 115-144. 